\title{
O CONFRONTO CRÍTICO DE ARENDT COM JASPERS E HEIDEGGER
}

\author{
Kherlley Caxias Batista Barbosa ${ }^{1}$
}

\section{RESUMO}

A Filosofia Política de Arendt afunda raízes no pensamento existencial de Heidegger e Jaspers. Este trabalho tenta mostrar a apropriação crítica que Arendt faz dos seus mestres, salientando a aproximação e o distanciamento do pensamento arendtiano em relação à filosofia existencial na formação de sua original filosofia política.

Palavras-chave: Arendt. Heidegger. Jaspers. Filosofia Política. Filosofia Existencial.

\footnotetext{
${ }^{1}$ Professor Adjunto do Curso de Filosofia da Universidade Federal do Tocantins (UFT). Licenciado em Filosofia pela Pontifícia Universidade Católica de Goiás, Bacharel e Mestre em Teologia pela Pontificia Facoltà San Bonaventura-Roma/Itália. Doutor em Filosofia pelo Programa de Pós-Graduação de Filosofia da Universidade do Vale do Rio dos Sinos - UNISINOS/RS.
} 


\begin{abstract}
Arendt's Political Philosophy is rooted in the existential thinking of Heidegger and Jaspers. This paper tries to show the critical appropriation that Arendt makes of her masters, emphasizing the approximation and the distancing that Arendt's thought creates in relation to the existential philosophy in the process of formation of her original political philosophy.
\end{abstract}

KEYWORDS: Arendt. Hedegger. Jaspers. Political Philosophy. Existencial Philosophy. 


\section{INTRODUÇÃ̃ ${ }^{2}$}

Neste trabalho, busco apresentar parte da gênese da filosofia política de Hannah Arendt, indicando o modo como se apropria do pensamento filosófico de Martin Heidegger e de Karl Jaspers. A apropriação arendtiana da filosofia existencial segue um movimento de dúplice sentido, ora de aproximação e ora de distanciamento, configurando-se como uma apropriação crítica em que a influência do pensamento existencial não só não impediu como possibilitou a independência do pensamento político arendtiano.

Heidegger e Jaspers foram os principais mestres na formação filosófica ${ }^{3}$ de Arendt. Com eles, Arendt manteve um debate e um diálogo constantes, de modo que foram importantes não apenas no início de sua trajetória filosófica, mas ao longo da maturação de sua filosofia política.

\section{O debate de Arendt com Heidegger}

Nos seus escritos, Arendt mantém um debate profundo com Heidegger. No início, era uma discípula fascinada pelo mestre, mas no processo de maturação de seu pensamento, tornou-se uma dura crítica, embora reconhecesse o débito para com seu antigo professor e amigo, com quem pôde ter a experiência do autêntico pensar filosófico. ${ }^{4}$

A exposição que faço do debate de Arendt com Heidegger vai seguir os passos seguintes: primeiramente, apresento as posições dos intérpretes do pensamento de Arendt que discutem a

\footnotetext{
${ }^{2}$ Nas citações das obras de Arendt, adoto o seguinte padrão: abreviatura da obra, número da página em inglês, seguido do número da página da tradução em português, quando for o caso. A abreviatura de cada obra foi colocada nas Referências.

${ }^{3}$ No período de sua formação filosófica, Arendt não se ocupa com a filosofia política propriamente dita, mas com a grande tradição da filosofia alemã. Arendt esclarece que sua formação filosófica tem origem na tradição da filosofia alemã. "Eu não sou um dos "intelectuais que vieram da esquerda alemã" ... eu cheguei tarde a uma compreensão da importância de Marx porque não estava interessada nem em História nem em Política quando era jovem. Se se pode dizer que "vim de algum lugar", é da tradição da filosofia alemã". (JW, p. 466)

${ }^{4}$ Passados muitos anos, Arendt relembra da novidade que Heidegger trouxe para a filosofia na Alemanha: "A novidade simplesmente dizia: o pensamento tornou a ser vivo, ele faz com que falem os tesouros culturais do passado, considerados mortos, e eis que eles propõem coisas totalmente diferentes do que desconfiadamente se julgava. Há um mestre; talvez se possa aprender a pensar”. (LET, p. 151/222-23)
} 
influência de Heidegger na sua filosofia política, e, em seguida, analiso textos em que Arendt se debruça sobre o pensamento de Heidegger.

\section{A apropriação do pensamento heideggeriano}

A relação do pensamento de Arendt com o de Heidegger manifesta dois movimentos: um de aproximação e outro de distanciamento, configurando uma relação tanto de continuidade como de descontinuidade, que, segundo André Duarte, cria "um campo de proximidade em meio a distância". 5 Para os estudiosos que tratam desta relação, a filosofia de Arendt representa, de fato, uma apropriação do pensamento de Heidegger, mas uma apropriação de tipo crítica. ${ }^{6}$

Para Hinchman e Hinchman, a relação de Arendt com Heidegger, mesmo sendo ambígua no âmbito pessoal, manteve-se coerente no campo teórico. Se no âmbito pessoal, Arendt, primeiramente, indignou-se com a adesão do mestre ao partido nazista, rompendo relações com ele e as reatando com o passar dos anos, no âmbito teórico conservou do início ao fim a crítica à filosofia heideggeriana. ${ }^{7}$ Para esses intérpretes, a apropriação arendtiana da filosofia de Heidegger é patente na descrição do modo de ser do Dasein no espaço e no tempo; na centralidade da análise da linguagem, sobretudo, da linguagem original que é desvelada com o recurso da etimologia, que descortina não apenas o significado primordial dos termos, mas também as experiências que lhes são subjacentes. No seu estudo acerca do "débito" de Arendt para com Heidegger, Hinchman e Hinchman enfatizam que a presença de Heidegger nas obras

\footnotetext{
${ }^{5}$ Duarte sustenta que o pensamento de Arendt mantém uma relação de aproximação e distanciamento com o do seu ex-mestre; aproximação porque apreende "certos princípios fundamentais para sua interpretação crítica da tradição filosófica ocidental" e se afasta das deficiências políticas de Heidegger, "na medida em que as pensa como inseridas no campo da hostilidade tradicional da filosofia em relação à política". Assim, Arendt difere fundamentalmente de Heidegger "no que respeita à compreensão da tarefa do pensamento e de seu vínculo com os eventos políticos particulares do mundo." (DUARTE, 2000, p. 320-21)

6 Nesta discussão, utilizo: DUARTE, 2000.; VILLA, 1996.; TAMINIAUX, 1997; HINCHMAN, L. and HINCHMAN, S. 1984.

7““A relação de Arendt com Heidegger é extremamente ambígua. Ela ficou consternada e irritada com a adesão à tomada de poder do Nazismo... Mas durante os anos do pós-guerra, Arendt conseguiu de alguma maneira reparar sua relação com Heidegger e continuou a estudar seus escritos cuidadosamente ... Nós argumentamos que seu julgamento fundamental acerca do pensamento de Heidegger permaneceu estritamente coerente ... desde o início até o fim ela criticou seu suposto isolamento do conjunto dos assuntos humanos. " (HINCHMAN, L.; HINCHMAN, S., 1984, p. 189)
} 
de Arendt se dá no elaborado sistema de distinções e conceitos, no modo de lidar com a linguagem e na interpretação da ação como auto-revelação. ${ }^{8}$

Por outro lado, ressaltam a ruptura (break) que Arendt faz em relação à filosofia de Heidegger, na forma de uma crítica à noção de "Eu" autêntico isolado do mundo, à desvalorização do espaço público, à anulação da vontade na passividade do "querer nãoquerer" e à identificação do pensar com o agir.

Para Jacques Taminiaux, Arendt assimilou as questões "urgentes" levantadas por Heidegger no período da elaboração de sua ontologia fundamental, mas as respostas ${ }^{9}$ dadas a essas questões na sua filosofia política romperam com a perspectiva do pensamento do exmestre:

A comparação textual das conferências precedentes a Ser e Tempo com A Condição Humana foi suficiente para me convencer de que seu trabalho não teria sido possível sem o ensinamento de Heidegger. Essa foi a condição necessária para suas investigações, mas de modo algum foi a condição suficiente ... porque assim que se confronta o que Arendt diz sobre "mundo", "trabalho", "discurso", o "politico", com o que Heidegger diz, não pode falhar em perceber que Arendt, longe de ser um epígono de Heidegger, em todos estes temas oferece uma réplica a ele. (TAMINIAUX, 1997, p. x)

Dana Villa também insiste na influência de Heidegger no pensamento de Arendt, mas ressalva que, não obstante esse fator, a originalidade do pensamento de Arendt é transparente. Para ele, a mudança paradigmática que Heidegger trouxe para a filosofia serviu de conditio sine qua non da filosofia política arendtiana. "Paradoxalmente, o pensamento de Heidegger providenciou o pano de fundo absolutamente essencial para Arendt repensar o político: sem essa "mudança de paradigma", seu projeto seria inimaginável". (VILLA, 1996, p. 13) Mas, segundo ele, a apropriação que Arendt faz de Heidegger é feita de "maneira altamente agonística" porque a discípula reinterpreta o mestre para desenvolver uma teoria política que, apesar do débito para com ele, critica radicalmente o seu pensamento:

\footnotetext{
${ }^{8}$ Cf. HINCHMAN, L.; HINCHMAN, S., 1984, p. 196.

${ }^{9}$ Tomando por base os estudos de Heidegger anteriores a Ser e Tempo, e os seminários que Arendt participou na fase de amadurecimento da ontologia fundamental, sobretudo o seminário sobre $O$ Sofista de Platão, Taminiaux sustenta que as noções fundamentais da filosofia política de Arendt, como mundo, práxis, condição humana e o lugar da filosofia e o papel dos filósofos, são uma "réplica" arendtiana à posição de Heidegger sobre esses temas. (Cf. TAMINIAUX, 1997, p. 3-17)
} 
Ao enfatizar o débito de Arendt para com o pensamento de Heidegger, não é minha intenção reduzir sua filosofia política ao status de uma nota de rodapé de outra pessoa... Eu vejo que Arendt apropria-se de Heidegger num modo altamente agonístico, revirando, deslocando e reinterpretando seu pensamento em formas projetadas para iluminar uma gama de questões extremamente não-heideggerianas ... o fato permanece de que sua teoria política, mais do que qualquer outra, "retoma" o pensamento de Heidegger com a tarefa de repensar o político. No processo, ela nos fornece instrumentos para a mais poderosa e convincente crítica da filosofia política dele. (VILLA, 1996, p. 13)

Villa ressalta que a mudança de paradigma da noção de liberdade feita por Heidegger tornou-se basilar para o repensamento político que Arendt faz da liberdade, para a compreensão da liberdade como uma realidade mundana, ${ }^{10}$ isto é, como atividade da ação. A finitude, a contingência, e a mundaneidade enquanto elementos estruturais da liberdade humana são categorias do pensamento heideggeriano apropriadas por Arendt. Com base nessa herança heideggeriana, para o autor, Arendt elabora o conceito de liberdade que reflete a objetividade do mundo e não a subjetividade das atividades humanas.

A abordagem ontológica da liberdade humana por Heidegger (o que eu chamei de "mudança de paradigma") claramente prepara o terreno para a narrativa própria de Arendt, no sentido duplo que questiona a prioridade da vontade e insiste na finitude, na contingência e na mundaneidade como aspectos estruturais da liberdade humana. (VILLA, 1996, p. 122)

Assim, a filosofia de Heidegger é um ponto de arranque a partir do qual Arendt desenvolve sua crítica aos limites do pensamento filosófico no tocante à filosofia política, incluindo nessa crítica a filosofia do próprio Heidegger, ironicamente. ${ }^{11}$ De modo que a apropriação que Arendt faz da filosofia heideggeriana é, a justo título, caracterizada como uma "apropriação de natureza transformadora". 12

\footnotetext{
10 “A abordagem ontológica de Heidegger à questão da liberdade humana acarreta uma mudança radical de paradigma, uma guinada que acaba por ser absolutamente central para o pensamento da liberdade enquanto 'tangível realidade mundana"'. (VILLA, 1996, p. 114)

${ }^{11} \mathrm{O}$ resultado anti-heideggeriano da apropriação de Heidegger é que a autenticidade da existência é espacializada; onde Heidegger via a queda e inautenticidade do Dasein, na sua relação com os outros, Arendt identifica a possibilidade da individualização do agente, na esfera pública, espaço da opinião e da comunicação.

${ }^{12}$ Por exemplo: a distinção heideggeriana entre existência autêntica e inautêntica é apropriada por Arendt, mas com um deslocamento, já que a vida autêntica para Arendt se dá na esfera pública, enquanto que para Heidegger autenticidade supõe o distanciamento do mundo e o refúgio na morada do "Eu".
} 


\section{O confronto crítico com o mestre}

Os estudiosos que tratam da presença da filosofia de Heidegger no pensamento de Arendt assinalam a imprescindibilidade de contextualizar o pensamento arendtiano partindo da influência de Heidegger. Tendo como pano de fundo as caracterizações acima, que indicam ser Heidegger uma fonte necessária, mas não suficiente da filosofia política de Arendt, passo, em seguida, a condensar o posicionamento de Arendt em relação à filosofia de Heidegger, considerando tão somente os textos em que Arendt lida diretamente com o pensamento do exmestre a fim de caracterizar no debate com ele o que realmente Arendt disse contra o mestre.

Deixando de lado sua tese $O$ conceito de Amor em Santo Agostinho, em que estão presentes "os métodos de pensar que Arendt aprendeu de seus professores, Heidegger e Jaspers" (YOUNG-BRUEHL,1997, p. 427) é num texto do pós-guerra, O que é Filosofia da Existência ${ }^{13}$, que Arendt apresenta a interpretação da filosofia existencial de ambos.

Para Arendt, a filosofia existencial de Heidegger restabelece a coincidência entre essência e existência ${ }^{14}$, que tinha sido perdida na crítica kantiana à unidade entre o Pensamento e o Ser ${ }^{15}$, e assume a impossibilidade do conhecimento da essência do homem. Segundo Arendt, Heidegger:

... declara ter encontrado um ser em que a essência e a existência são idênticas, e que este ser é o homem. 'A substância do homem não é espírito (...) mas existência'. (Heidegger) $\mathrm{O}$ homem não tem substância; ele consiste no fato de que ele existe. Não podemos indagar o Quê do homem no modo que podemos indagar o Quê de uma coisa. Somente podemos indagar o Quem do homem. (EU, p.177/206)

\footnotetext{
${ }^{13}$ Neste texto de 1946, Arendt apresenta uma breve história da filosofia da existência, destacando Schelling, Kierkegaard, Kant, Husserl, Heidegger e Jaspers. A sua reflexão inicia com a dissolução da unidade entre o Pensamento e o Ser na filosofia pós-kantiana, passando a tratar da filosofia da existência com base na cisão entre o conhecimento do mundo objetivo e o conhecimento da realidade do sujeito humano: "O ponto de partida de Kierkegaard é o sentimento do indivíduo de estar perdido num mundo totalmente explicado. O indivíduo se encontra em constante contradição com esse mundo explicado porque sua "existência", isto é, o próprio fato de seu existir arbitrário ... não pode ser previsto pela razão, nem reduzido por ela a algo puramente pensado" (EU, p. 173/203). Utilizo o texto da tradução do alemão Was ist Existenz-Philosophie publicado na coletânea Essays in Understanding, traduzido para português em Compreender, comparando-o com outra versão, What is Existenz Philosophy?, publicada na Partisan Review, em 1946.

${ }^{14}$ O significado de existência para Arendt: "O termo "existência" designa simplesmente o Ser (Sein) do homem, a despeito de todas as qualidades e capacidades que um indivíduo possa ter e que são acessíveis à investigação psicológica". (EU, p. 163/192).

${ }^{15}$ Arendt chama a atenção para o fato que essa identificação entre essência e existência fora elaborada pela metafísica tradicional na definição do ser de Deus. Essa ideia de Heidegger é, para ela, a tentativa de converter o homem em "Senhor do Ser". (EU, p. 177/206)
} 
O homem, cuja essência e existência coincidem, é o Dasein. Heidegger realiza, em Ser e Tempo, uma descrição fenomenológica do Dasein que, para Arendt, cai num tipo de funcionalismo, já que a analítica existencial abrange apenas as funções ou modos de ser do Dasein. ${ }^{16}$ Esse funcionalismo expõe deficiências por não conter uma ideia de homem capaz de dar unidade às diferentes funções. De acordo com Arendt, na filosofia heideggeriana, 'o 'Eu' ocuparia o lugar do homem, no sentido de que a principal característica do Dasein é que 'em seu Ser ele se refere a si mesmo"” (EU, p. 178/207). ${ }^{17}$

Segundo Arendt, Heidegger desvela que a principal atividade do Dasein é o cuidado de si, que reclama da parte do Dasein o isolamento do mundo e a anulação da relação com os outros, o "Eles", para voltar-se para o seu próprio "Eu”. A necessidade do movimento autorreflexivo faz surgir a questão: por que o Dasein, que é um 'ser-no-mundo', precisa se retrair na solidão do seu 'Eu”? Porque o Dasein, no seu ser 'lançado' no mundo, não encontra nesse aí do mundo, sua autêntica morada. A experiência do Dasein com os outros seres humanos no mundo é uma experiência de alienação, de queda, de culpa, em suma, de inautenticidade. ${ }^{18}$ Somente ouvindo o chamado da sua consciência, e voltando-se para o seu "Eu”, pode o Dasein encontrar a resposta para a pergunta pelo seu próprio ser. A pergunta pelo seu ser é feita na antecipação reflexiva da morte, momento em que o Dasein reconhece que a existência é marcada pelo nada e pela dissolução do fato de existir. "O Ser no sentido heideggeriano é o Nada". (EU, p. 176/205). Esse significado do Ser é a base da "resolução" do Dasein, isto é, da atitude assumida a partir da consciência da condição de ser finito e mortal.

\footnotetext{
${ }^{16}$ Esse funcionalismo "descarta todas aquelas características humanas ... como liberdade, dignidade humana e razão que brotam da espontaneidade humana... visto que, como características espontânea, são mais do que meras funções do ser, e porque nelas o homem ultrapassa a si mesmo". Nessa perspectiva funcionalista que prescinde da espontaneidade humana o homem não é mais que "um aglomerado de modos de ser ... visto que não há nenhuma ideia de homem a guiar a seleção dos modos de ser." (EU, p. 178/207)

${ }^{17}$ A autorreflexividade do Dasein é o ato filosófico primordial. Assim, Heidegger reformula o bios theoretikos de Aristóteles. A vida contemplativa, desta vez ensimesmada, continua sendo valorizada como a vida mais elevada do homem, com a diferença de que o ser contemplado, o summum ens, não é mais o Deus da tradição metafísica, mas o ser do homem, isto é, sua existência. (Cf. EU, p. 178/207)

${ }^{18}$ Arendt reconhece que a filosofia de Heidegger "é a primeira absoluta e inflexivelmente terrena. O elemento crucial do ser do homem é ser-no-mundo, e o que está em questão para seu ser-no-mundo é pura e simplesmente sua sobrevivência no mundo" (EU, p. 179/208). Mas o mundo não é garantia da sobrevivência do Dasein, gerando a ansiedade pelo fato da morte. O mundo se torna uma realidade estranha e alienada para o Dasein.
} 
Arendt desnuda o individualismo do Dasein. O "Eu" individual encontra-se separado do convívio com os outros, afastado do mundo e na vivência autorreflexiva reconhece sua condição de ser finito e mortal:

O caráter essencial do Eu é sua absoluta Eu-dade ${ }^{19}$, sua separação radical de todos os semelhantes...é na morte que o homem realiza o principipium individuationis absoluto. Apenas a morte o retira da ligação com seus semelhantes, os quais, enquanto 'Eles', constantemente o impedem de ser um Eu. Embora a morte seja o fim do Dasein, ao mesmo tempo é a garantia de que tudo o que importa, ao fim e ao cabo, sou eu mesmo... o que surge desse isolamento absoluto é um conceito do Eu como absoluto oposto do homem. (EU, p.181/209-10)

Para Arendt o individualismo do Dasein é a base para uma compreensão da vida comum cuja característica principal é a atomização do indivíduo. Como o Eu é incapaz de se constituir autenticamente no convívio humano no mundo, resta apenas uma "conciliação mecânica" entre os diferentes 'Eus'. Arendt, nessa linha interpretativa, mostra que na ontologia fundamental de Heidegger está ausente um “conceito de homem” que considere "seu convívio na terra com seus semelhantes”. (EU, p. 181/210)

Este texto fundamental apresenta a mais dura crítica de Arendt a Heidegger, centrada no funcionalismo descritivo do Dasein, no individualismo do 'Eu', e na atomização do indivíduo, bem como na continuidade da tradição que considera o bios theoretikos como o tipo de vida mais autêntico do ser humano. Encontram-se aqui os temas centrais de um contínuo debate em que Arendt fará uma contraposição ${ }^{20}$ às posições de Heidegger na elaboração de sua filosofia política. ${ }^{21}$ Em O Interesse do Atual Pensamento Filosófico Europeu pela Política,

\footnotetext{
${ }^{19}$ Este termo é a tradução de "Self-ness", que aparece no texto de Essays in Understanding (EU, p. 181), mas na versão do Partisan Review o termo usado é egoism (cf. p. 50).

${ }^{20}$ A fim de ilustrar essas contraposições, basta mencionar aqui o tema da individuação: Arendt concorda com Heidegger de que não é atividade da fabricação que individualiza o ser humano, mas a praxis. No entanto, Arendt não segue a articulação que Heidegger faz entre a individuação e o ser-para-a-morte do Dasein, pelo contrário, "Arendt coloca o ônus da individuação no que ela chama de "natalidade", concebida não como uma mera emergência da zoé, mas como uma capacidade de iniciar algo excepcional e imprevisível". (TAMINIAUX, 1997, p. 16).

${ }^{21}$ Para Hinchman e Hinchman, 1984, p. 203: “... o artigo nos dá algumas valiosas evidências a respeito das linhas que o pensamento de Arendt tinha seguido no ano que estudou sob a direção de Heidegger" Segundo um duro crítico de Arendt, esse artigo “... definiu bem suas atitudes depois que ela tinha aparentemente seguido além dele ... mesmo que não tenha feito referência às implicações políticas da Existenzphilosophie, retrospectivamente pode-se ver que muitos dos temas explicitados no seu subsequente trabalho sobre a política foram desenvolvidos em termos estritamente filosóficos neste ensaio." (JAY, Martin., 1985, p. 239-40) Também Taminiaux (1997, p.10): "se nós consideramos este pequeno escrito em retrospectiva e a partir do seu
} 
Arendt analisa o teor político dos conceitos heideggerianos de mundo e de historicidade. Sustém que o conceito de historicidade de Heidegger tem como antepassado o conceito de história de $\mathrm{Hegel}^{22}$, mas que o conceito heideggeriano diferencia-se do conceito hegeliano porque para Heidegger na história humana "não se revela nenhum absoluto e nenhum espírito transcendente". (EU, p. 432/448) Esse conceito de historicidade despido de referência a parâmetros de juízo absolutos e transcendentes torna-se essencial na adoção de uma nova atitude do filósofo para com a política:

Em nosso contexto, isso significa que o filósofo deixou para trás a pretensão de ser "sábio" e de conhecer os moldes eternos dos assuntos efêmeros da Cidade dos homens, pois essa "sabedoria" só se justificaria a partir de um ponto fora do âmbito dos assuntos humanos, e só poderia ser considerada legítima em virtude da proximidade do filósofo junto ao absoluto. No contexto da crise espiritual e política da época, significa que o filósofo, junto com todos os demais, tendo perdido o quadro tradicional dos chamados valores, não buscará o restabelecimento dos antigos nem a descoberta de novos valores. (EU, p. 432/448)

A partir deste conceito de historicidade, a história humana é vista pelo filósofo desde dentro e não desde um modelo absoluto, vindo de fora. A filosofia que abre mão de ser sabedoria e de aplicar no campo histórico os padrões eternos de conhecimento e de juízo se dá como tarefa "o reexame de todo o âmbito da política à luz das experiências humanas básicas nesse campo e implicitamente descarta conceitos e juízos tradicionais com raízes em tipos diferentes de experiência". (EU, p. 432/448)

É fundamental assinalar que essa nova postura do filósofo se afigura como essencial para uma filosofia que busca o sentido das experiências autênticas do fenômeno político, como é o caso da filosofia arendtiana. ${ }^{23}$

subsequente trabalho, não podemos falhar em notar neste a proclamação, por assim dizer a contrario, não de uma acordo subsequente, mas de um debate com Heidegger".

${ }^{22}$ Esse conceito, segundo Arendt, "conferiu ao campo dos assuntos humanos uma dignidade da qual nunca desfrutara". (EU, p. 430/446) O pensamento e os acontecimentos humanos são eventos históricos. "A ligação entre pensamento e acontecimento parecia indicar que o próprio pensamento é histórico, e nem o filósofo (por exemplo, a coruja de Minerva hegeliana) nem o que ele pensa (por exemplo, os modos hegelianos do Absoluto) estão fora da história ou revelam algo que está fora da história". (EU, 4312/447)

${ }^{23}$ Nessa linha de busca, a tarefa da filosofia política consiste em recolocar as questões fundamentais do político a partir da nova perspectiva. Assim, essa nova filosofia política não pode olvidar, na formulação da sua agenda, “... as questões mais permanentes da ciência política e, em certo sentido, mais especificamente filosóficas - como: $o$ que é a política? Quem é o homem enquanto ser político? O que é a liberdade? ” (EU, p. 449/433; grifo meu) 
A apropriação arendtiana do conceito de historicidade de Heidegger significa sua adesão ao projeto de uma filosofia antimetafísica, pressuposto para um pensamento sobre o fenômeno político sem o amparo de fundamentos externos ao âmbito da política. Entretanto, como a sua apropriação de Heidegger é crítica, Arendt aponta a limitação deste conceito heideggeriano na formulação de uma filosofia política, devido à "incapacidade de atingir o ponto fulcral da política - o homem como ser de ação" (EU, p. 433/449).

Heidegger não faz um "reexame" da política porque na sua filosofia a esfera dos assuntos mundanos não é o espaço da vida autêntica. Nesse sentido, a perspectiva da filosofia heideggeriana - mesmo tendo rompido com o pensamento filosófico tradicional metafísico conserva, segundo Arendt, o tradicional desdém da filosofia pela política:

... reencontramos a velha hostilidade do filósofo em relação à polis nas análises heideggerianas da vida cotidiana normal em termos de das Man (o "eles" ou o domínio da opinião pública, em oposição ao "eu”), em que o âmbito público tem a função de ocultar a realidade e até de impedir o surgimento da verdade. (EU, p. 432/448)

Não obstante o seu juízo da hostilidade de Heidegger pela política, Arendt encontra no conceito de homem enquanto ser-no-mundo uma via para a filosofia superar seus pressupostos internos, e tornar-se capaz de reexaminar a importância do mundo,

... como Heidegger define a existência humana como ser-no-mundo, ele insiste em conferir uma importância filosófica a estruturas da vida cotidiana que seriam totalmente incompreensíveis se não se compreendesse o homem, em primeiro lugar, como um ser com os outros. (EU, p. 443/459)

Não deixa de ser irônica, a recuperação que Arendt faz das análises heideggerianas do ser-no-mundo. A ironia surge porque Arendt usa Heidegger contra Heidegger contrapondo ao solipsismo existencial - criticado em $O$ que é Filosofia da Existência- a noção de ser mundano. Arendt encontra no próprio Heidegger o antídoto para o veneno heideggeriano. Ademais, urge destacar que, nesse texto, que explicita o esforço de traçar a via de uma "ciência política" com viés filosófico, Arendt assume um tom diferente na avaliação da filosofia de Heidegger. Ressaltando a relevância dos conceitos de historicidade e de ser-no-mundo para repensar os assuntos humanos, Arendt realiza uma apropriação de conceitos filosóficos de Heidegger orientando-os para o propósito de construção de uma filosofia política sem fundamentos metafísicos. 
Consciente de que "Heidegger nunca tratou das implicações políticas de sua filosofia" (EU, p. 446/477), Arendt ao se apropriar destes conceitos não apenas expande a filosofia de Heidegger para um terreno inexplorado por ele, mas se distancia de Heidegger no curso da criação de uma filosofia propriamente política. A postura crítica que Arendt assume diante da filosofia de Heidegger revela, neste texto, a dialética de continuidade e descontinuidade que caracteriza o debate dela com seu ex-mestre.

A dura crítica de Arendt à filosofia heideggeriana poderia suscitar objeções de toda sorte. No entanto, a defesa do pensamento de Heidegger face à crítica arendtiana resvala na declaração do próprio Heidegger, que reconheceu que a interpretação de Arendt atingiu o fulcro do seu pensamento. Heidegger, em carta a Arendt, confidenciou: “... mais do que qualquer outro, você tocou o movimento profundo do meu pensamento e do meu trabalho como professor, que restou o mesmo desde o curso Sofista" (LET, p. 163).

\section{O diálogo de Arendt com Karl Jaspers}

Denomino de diálogo a relação de Arendt com Jaspers para diferenciar do termo debate, usado para caracterizar o confronto com Heidegger. Arendt via em Jaspers o único professor que ela reconheceu como tal, capaz de educar em liberdade. ${ }^{24}$ Com Jaspers a relação foi diferente, foi um diálogo contínuo entre a discípula e o mestre, que "concordavam em todas as questões básicas" (COR., n. 486). A postura humana de Jaspers e sua peculiar forma de fazer filosofia eram um modelo para Arendt. A afinidade entre Arendt e Jaspers verificavase no modo de compreender o papel da filosofia na experiência de pensar no mundo, com os homens que nele habitam. A filosofia existencial de Jaspers abriu o caminho que Arendt explorou e desenvolveu na teoria política ${ }^{25}$.

Numa entrevista, quando indagada se Jaspers foi sua maior influência, Arendt respondeu:

Bem, onde quer que Jaspers apareça e fale, tudo se ilumina. Ele tem uma desenvoltura, uma confiança, uma incondicionalidade no discurso que eu

\footnotetext{
${ }^{24}$ Cf. COR, n. 140.

${ }^{25}$ Comentando um texto de Jaspers, em 1949, Arendt diz: “... novamente ficou claro para mim - embora não tivesse consciência disso naquele tempo - o quanto sua filosofia me preparou para a política". (COR, p.133.)
} 
nunca reconheci em nenhuma outra pessoa. Isso me impressionou desde quando eu era muito jovem. Além disso, ele tem uma concepção de liberdade ligada à razão que era completamente estranha para mim quando fui para Heidelberg. Não sabia nada a respeito daquilo, embora tivesse lido Kant. Vi essa razão em ação, por assim dizer. E, se posso dizer assim - cresci sem pai - aquilo me educou. Não quero torná-lo responsável por mim, pelo amor de Deus, mas se alguém conseguiu me instilar algum senso das coisas, E esse diálogo, claro, hoje é totalmente diferente. Foi sem dúvida minha experiência pós-guerra mais ponderosa. (EU, p. 52/22)

\section{A filosofia da existência de Jaspers}

Arendt expõe uma aguda crítica a Heidegger no artigo $O$ que é filosofia da existência?, mas não adota a mesma acidez com Jaspers. Na realidade, "em relação à ontologia fundamental de Heidegger, este artigo é equivalente a uma violenta rejeição em nome de Jaspers e sua filosofia da comunicação” (TAMINIAUX, 1997, p. 9).

Neste texto, Arendt passa pelos temas da filosofia da existência de Jaspers, detendo-se especialmente nos conceitos de comunicação, de existência e de liberdade. A comunicação ${ }^{26}$ é o modo de fazer filosofia. A filosofia é uma troca comunicativa entre sujeitos iguais que compartilham um mundo comum com o propósito de 'iluminar' a existência. Arendt associa o modo de fazer filosofia de Jaspers ao de Sócrates, porque ambos filosofam em meio aos homens, e não no isolamento. A filosofia nos dois filósofos é exercida na convivência mundana e humana. O filósofo não vive uma existência separada dos outros homens para realizar a experiência do pensamento.

Se o escopo da filosofia comunicativa é iluminar a existência, cabe perquirir o significado da existência humana na filosofia de Jaspers. Diz Arendt:

Para Jaspers, a existência não é uma forma do Ser, mas uma forma de liberdade humana, a forma em que o "homem como espontaneidade potencial rejeita a concepção de si mesmo como mero resultado". A existência não é o ser do homem como dado e enquanto tal: pelo contrário, "o homem é, no Dasein, uma existência possível". A palavra "existência", aqui, significa que o homem alcança a realidade apenas à medida que age a partir de sua liberdade enraizada na espontaneidade e "se conecta, por meio da comunicação, com a liberdade dos outros. (EU, p. 183/212)

\footnotetext{
26 “Comunicação é a forma por excelência de participação filosófica, que é ao mesmo tempo um filosofar em comum, cuja finalidade não é gerar resultados, e sim 'iluminar" a existência””. (EU, p. 211/183)
} 
A filosofia não é o conhecimento do Ser como é dado, mas um pensar que busca transcender a limitação do conhecimento do ser dado. Na transcendência da filosofia se encontra a liberdade. A Filosofia, na sua diferença em relação ao conhecimento objetivo, é o empenho em pensar a "existência livre que está sempre tentando transcender esse mundo meramente dado". (EU, p. 185/214).

A existência não é apenas um dado factual. A existência se diferencia do simples fato de ser, do mero estar aí, do existir pura e simplesmente. Como se dá essa diferenciação entre o mero existir e existência? Por meio da ação, "que surge das "situações-limite"27 e "entra no mundo por meio da comunicação com os outros” (EU, p. 184/213). É na experiência das "situações-limite" que o homem reconhece o potencial da ação, o que pode e não pode fazer, para deixar de ser um mero dado natural ("ser um resultado") e se tornar uma "existência" na comunicação com os outros. Existência e comunicação se imbricam porque a ação que constitui a existência não é uma atividade interior do $\mathrm{Eu}$, mas uma atividade que acontece na relação comunicativa com os outros. Nesse ponto que salienta a dimensão relacional e comunicacional da existência é patente a diferença das filosofias de Jaspers e Heidegger, que Arendt, a propósito, destaca:

A existência em si, por sua própria natureza, nunca é isolada. Existe apenas na comunicação e na consciência da existência dos outros. Nossos semelhantes não são (como em Heidegger) um elemento da existência que, embora estruturalmente necessário, é ao mesmo tempo um impedimento ao Ser do Eu. Muito pelo contrário, a existência só pode se desenvolver na vida compartilhada dos seres humanos que habitam num mundo dado, comum a todos eles. No conceito de comunicação encontra-se um novo conceito de humanidade, cuja abordagem, mesmo ainda não plenamente desenvolvida, postula a comunicação como a premissa para a existência do homem... os seres humanos vivem e agem entre si; assim procedendo, não perseguem o fantasma do Ser, nem vivem na ilusão arrogante de constituírem o próprio Ser. (EU, p. 186/215)

27 A liberdade humana é marcada "pelas situações-limite em que o homem vivencia as limitações que determinam diretamente as condições de sua liberdade e lhe dão a base para as suas ações. A partir dessas dimensões, ele pode "iluminar" sua existência e definir o que pode e não pode fazer. E assim ele pode passar do mero "ser-um-resultado" para a "existência", a qual para Jaspers, é apenas um outro termo para ser humano num sentido determinado" (EU, p. 186/215). 
A importância do conceito de comunicação para a noção de existência é uma lição fundamental que Arendt extrai da filosofia de Jaspers e expressa em $O$ que é filosofia da existência? Mas ao mesmo tempo que Arendt explora a dimensão prática ${ }^{28}$ e política do conceito de comunicação detecta os limites desse conceito. O aspecto positivo que Arendt extrai do conceito reside no fato de que a comunicação se dá entre homens que criam um espaço de revelação, estabelecendo um vínculo entre eles. Essa concepção de comunicação tem um profundo enraizamento em "experiências políticas muito antigas e autênticas", que remontam às definições aristotélicas do zoon politikon e do logon echon que expressam que a atividade política é possível à medida que o homem é capaz de realizar o discurso compreensivo e persuasivo. $\mathrm{O}$ aspecto negativo do conceito vem indicado por Arendt em $O$ Interesse do atual pensamento filosófico europeu pela política e diz respeito à forma da comunicação enquanto diálogo pessoal entre "Eu e Você", uma experiência que se aproxima mais da experiência da solidão do pensamento, do diálogo do eu consigo mesmo, do que da experiência da pluralidade de visões de mundo no âmbito da política. Para Arendt, essa face solitária do conceito de comunicação na filosofia de Jaspers traz uma dificuldade para seu uso no campo político.

As limitações da filosofia de Jaspers em termos políticos se devem, acima de tudo, ao problema que tem infestado a filosofia política ao longo de quase toda a sua história. Consiste na característica filosófica de lidar com o homem no singular, ao passo que nem seria possível conceber a política se os homens não existissem no plural. Ou, dito de outra maneira: as experiências do filósofo - como filósofo - se dão com a solidão, e para o homem - como político - a solidão é uma experiência essencial, mas mesmo assim marginal. (EU, p. 443/459)

Entretanto, essa crítica à noção de comunicação pode ser atenuada quando se toma em exame as reflexões de Arendt em Karl Jaspers: Cidadão do Mundo?. Neste texto, Arendt mostra que o conceito de comunicação de Jaspers é essencial para embasar uma filosofia política voltada para a pluralidade das tradições das nações. Uma filosofia mundial com base no diálogo entre as tradições dos diferentes povos. A comunicação é tomada como o princípio

\footnotetext{
${ }^{28}$ A comunicação não é uma "expressão" de ideias ou sentimentos, de forma que seria secundária a eles; a própria verdade em si é comunicativa e desaparece fora da comunicação. O pensar, na medida em que tenha alguma pretensão de atingir a verdade, deve necessariamente desembocar na comunicação, se torna prático, mas não pragmático. É uma prática exercida entre homens, e não tanto a atividade de um indivíduo em sua solidão voluntária". (EU, p. 457/441)
} 
que embasa uma filosofia da "unidade da humanidade". Nessa perspectiva da filosofia comunicativa de Jaspers, segundo Arendt, a identidade da humanidade pressupõe as identidades das tradições diferentes ${ }^{29}$, assim a unidade não é uniformidade, mas a consideração da multiplicidade no campo da cultura humana:

A unidade e a solidariedade entre a humanidade não podem consistir num acordo universal sobre uma única religião, ou uma única filosofia, ou uma única forma de governo, mas na fé de que o múltiplo aponta para um Uno, simultaneamente oculto e revelado pela diversidade. (MDT, p. 89/82)

Arendt abandona sua crítica à dimensão da singularidade do diálogo comunicativo passando a sublinhar que a filosofia comunicativa de Jaspers não é uma da filosofia do homem, do indivíduo singular, mas uma filosofia da pluralidade humana ${ }^{30}$; uma filosofia que é uma atividade prática entre homens, e não uma atividade contemplativa exercida por quem habita a morada da solidão. ${ }^{31} \mathrm{~A}$ dedicação aos assuntos mundanos, a busca da instauração do espaço de comunicação e de diálogo para superar a solidão do pensamento, a tentativa de dar novo significado ao conceito de homem, a ruptura com a tradição dogmática e metafísica são exemplos dos temas que alimentaram o diálogo de Arendt com Jaspers e que foram incorporados na sua filosofia política. Mas, o tema fundamental de Jaspers que irá reverberar ao longo e ao largo da filosofia política de Arendt é a existência qua liberdade.

\section{Liberdade e existência}

A compreensão da existência humana no pensamento de Arendt é marcada pela filosofia de Jaspers. Hinchman e Hinchman notam que a posição de Arendt sobre a existência

\footnotetext{
${ }^{29}$ Para Arendt a noção de humanidade comum que considera e não anula as tradições culturais diferentes carrega em si um conteúdo político: "o nacional de cada país só pode entrar nessa história mundial da humanidade se permanecer e aderir obstinadamente ao que ele é.” (MDT: p. 89/82) Nessa noção de humanidade encontramos um princípio de inclusão da diferença.

30 "Uma filosofia da humanidade se distingue de uma filosofia do homem pela sua insistência sobre o fato de que não o Homem falando consigo mesmo no diálogo da solidão, mas os homens falando e comunicando-se entre si habitam a Terra" (MDT, p. 90/82-3).

31 "Uma filosofia que ... abandonou a proverbial torre de marfim da mera contemplação. O pensamento se torna prático, ainda que não pragmático; é uma espécie de prática entre homens, não um desempenho de um indivíduo em sua solidão auto escolhida. Jaspers, tanto quanto sei, é o primeiro e único filósofo que sempre protestou contra a solidão" (MDT, p. 86/79).
} 
humana em A Condição Humana - segundo a qual o agente, o Quem (Who), revela-se na ação - tem estrita relação com a noção de Existenz de Jaspers. ${ }^{32}$

No famoso texto de 1946 sobre a filosofia existencial, repetidamente citado neste trabalho, Arendt afirma: "para Jaspers, a existência não é uma forma de Ser, mas uma forma de liberdade humana". A filosofia existencial discute dois modos de compreensão da existência humana: um modo que compreende o ser do homem como resultado, algo já dado, e o outro em que o existir humano vem compreendido como espontaneidade e possibilidade, isto é, como liberdade.

Para Jaspers, a existência não é uma forma de Ser, mas uma forma de liberdade humana, a forma em que o "homem como espontaneidade potencial rejeita a concepção de si mesmo como resultado". A existência não é o ser do homem como dado e enquanto tal: pelo contrário, "o homem é, no Dasein, uma existência possível". A palavra "existência", aqui, significa que o homem alcança a realidade apenas à medida que age a partir de sua liberdade radicada na espontaneidade e "se conecta, por meio da comunicação, com a liberdade dos outros. (EU, p. 183/212)

Os modos diferentes de compreender a existência humana assentam-se na distinção entre o ser como dado (resultado) e o ser como possibilidade. Enquanto ser dado ou mero existente o ser humano é o que resulta de um processo natural que engendrou seu existir. Nesse âmbito de realidade, o ser humano é objeto de conhecimento objetivo que trata das causas naturais que o trouxeram à existência. Obviamente que a filosofia existencial de Jaspers não nega o conhecimento objetivo do ser do homem, mas considera o ser do homem numa perspectiva diferente que defende a determinação não causal da existência humana. A Existenz difere-se do mero fato de existir porque está vinculada às ações do existente que brotam da sua espontaneidade. O ser enquanto pura existência dada é outro em relação ao ser que atualiza suas possibilidades pelas ações.

Como é possível ao ser humano tornar-se uma existência na diferença do mero fato de existir? Segundo Arendt: "existência, aqui, significa que o homem alcança a realidade apenas à medida que age a partir de sua liberdade radicada na espontaneidade". A Existenz é o ser humano enquanto ação, mas não é qualquer forma de ação, senão da ação radicada na

\footnotetext{
${ }^{32}$ Com base na análise dos textos de Jaspers, os autores descrevem o conceito de Existenz: “... o eu único que cada pessoa pode se tornar, mas que não é nem sujeito psicológico nem objeto, e igualmente não é uma "propriedade com a qual somos dotados por natureza". (HINCHMAN, L.; HINCHMAN, C., 1994, p. 146)
} 
espontaneidade. A ação, portanto, é a atividade em que está em jogo a existência do ser humano. A ação é a atualização da possibilidade da Existenz, que está ancorada à decisão de ser si mesmo. ${ }^{33}$

Dada a sinonímia entre espontaneidade e liberdade, a expressão "a liberdade radicada na espontaneidade" soa tautológica, mas não o é, já que manifesta duas dimensões distintas da noção de liberdade. A liberdade que é radicada na espontaneidade diz respeito à dimensão ativa, à ação livre, ou melhor, à liberdade qua ação, ao passo que a espontaneidade que é a radix da liberdade ativa refere-se à dimensão ontológica da liberdade ou à liberdade enquanto possibilidade e potencialidade que é atualizada na ação.

Essa distinção que separa as diferentes dimensões da liberdade, a dimensão ativa e a dimensão ontológica, é feita com base noutra distinção que diferencia o mero existir ou o ser dado, como dito por Arendt, do ser como forma de liberdade, isto é, como ser possível. É preciso ressalvar que o "ser radicado" da liberdade na espontaneidade, isto é, da liberdade ativa na liberdade ontológica, não significa o mesmo que ser fundado, como se o ser em que a liberdade se radica fosse uma potencialidade inclinada à atualização, como a potência em relação ao ato.

Em $O$ que é filosofia da existência? Arendt enuncia, mas não desenvolve a distinção entre liberdade da ação e liberdade da potência de agir (espontaneidade); no período em que escreveu essa reflexão ainda não tinha elaborado sua teoria da ação, que apareceu mais tarde em A Condição Humana. De qualquer maneira, sua interpretação da noção de Existenz de Jaspers já apresenta os indícios do caminho que irá trilhar na elaboração de sua filosofia política, na qual a liberdade é uma atividade mundana, mas enraizada na espontaneidade humana.

Portanto, Arendt se apropria da perspectiva existencial de Jaspers à medida que compreende a liberdade da ação política como enraizada na liberdade potencial. Essa liberdade potencial é a possibilidade e a capacidade de iniciar algo novo, realidade humana que Arendt designará na sua teoria da ação com o termo natalidade: "O milagre que salva o

\footnotetext{
${ }^{33}$ A Existenz "embora potencialmente existindo no poder do indivíduo, pode ser atualizada somente por uma decisão de ser si mesmo, de agir num modo tal que a vida exterior incorpora o eu que o indivíduo verdadeiramente é". (HINCHMAN, L.; HINCHMAN, C., 1994, p. 146; grifo dos autores)
} 
mundo, o domínio dos assuntos humanos, de sua ruína normal, "natural” é, em última análise, o fato da natalidade, no qual a faculdade da ação se radica ontologicamente". (HC, p. 308/247; grifo meu). A apropriação crítica arendtiana, contudo, alarga a perspectiva da filosofia existencial de Jaspers, pois situa a Existenz no âmbito político propriamente dito e analisa a existência no interior de uma teoria da ação, que não foi desenvolvida na filosofia de Jaspers.

\section{Conclusão}

O exame destes textos em que Arendt trata diretamente do pensamento de seus exmestres revela a presença da filosofia existencial na filosofia política de Arendt. $O$ debate/diálogo que Arendt manteve com Heidegger e Jaspers mostra que embora não tenha seguido o caminho da filosofia existencial, foi no confronto com essa filosofia que abriu o caminho para sua própria trilha de pensamento.

A definição de qual dos mestres mais influenciou o pensamento político de Arendt é uma questão espinhosa. A análise dessa influência precisa ser feita segundo o tema específico, e não sobre o pensamento de Arendt em geral. Um exemplo: a crítica ao solipsismo existencial do Dasein heideggeriano. Para Arendt, a resposta de Heidegger para a pergunta "Quem é o Dasein?" é insuficiente porque o Dasein enquanto ser aí precisa encontrar a solução para sua interrogação existencial no aí em que se encontra. Um passo para a resposta Arendt encontra na centralidade do conceito de comunicação e de diálogo da filosofia de Jaspers. O Eu é um ser dialógico que se mantém em relação com outros "Eus" na comunicação, portanto um ser não fechado em si. Contudo, Arendt encontra limites no conceito jasperiano de comunicação quanto a seu uso político, porque o diálogo instaurado na comunicação ainda se assemelha ao diálogo do pensamento, que ocorre na experiência da solidão. A saída para essa "saída" é um retorno a Heidegger, mas não ao Heidegger do "Eu" solipsista de O que é filosofia da existência?, mas ao Heidegger do Dasein como ser-no-mundo, exposto em $O$ interesse do atual pensamento filosófico europeu pela política.

Se colocássemos, hipoteticamente, a influência de Heidegger e Jaspers em cada um dos

pratos de uma balança, para qual dos lados a balança penderia mais? Segundo Betz, as maiores influências da filosofia de Arendt são Heidegger e Husserl de um lado e Jaspers e 
Sócrates do outro. De Heidegger, teria Arendt colhido os conceitos formais da filosofia, que se transformaram em ferramentas do seu pensamento, e de Jaspers teria extraído a motivação e o sentido de filosofar. Betz defende que Heidegger lhe concede os instrumentos e a linguagem filosófica, mas é de Jaspers que apreende a disposição filosófica e a "consciência filosófica". De modo que, o prato da balança penderia para Jaspers. ${ }^{34}$

A determinação do "peso" das filosofias de Heidegger e Jaspers na filosofia política de Arendt pressupõe a adoção de alguns textos ou temas a despeito de outros, sendo bastante problemático apresentar a solução, sem indicar qual o critério da escolha dos textos.

Com a noção de apropriação crítica resolvo a questão da seguinte maneira: Arendt recebeu forte influência de seus mestres da filosofia existencial, no debate e no diálogo com eles. Essa influência ocorre de duas maneiras: diretamente quando Arendt absorve uma questão ou um conceito e indiretamente quando mostra a insuficiência da posição deles; em ambos os modos é no quadro da relação com eles que Arendt elabora sua filosofia política. Assim, não me parece sustentável defender qual deles é mais influente no pensamento político de Arendt. Ambos são fios que Arendt entrelaça dando forma ao tecido do seu próprio pensamento político.

Como a filosofia existencial está na origem do pensamento de Arendt e não apenas no começo cronológico, trata-se da principal referência no terreno da filosofia para Arendt pensar os temas constituintes de sua filosofia política: o mundo, a ação, a pluralidade, o papel da filosofia, o método e a liberdade. Heidegger e Jaspers são os pensadores que Arendt segue para romper com uma concepção tradicional da filosofia. As contribuições deles para a reformulação da filosofia no desmantelamento da metafísica fornecem as condições para Arendt estabelecer a agenda da sua filosofia política. A tarefa dessa nova filosofia política consiste em eleger como tema fundamental o "ponto fulcral da política - o homem como ser de ação" e como questões centrais: "o que é a política? Quem é o homem enquanto ser político? O que é a liberdade? (EU, p. 433/449).

\footnotetext{
${ }^{34}$ A posição de Betz (2002, p. 76) ressalta a influência de Jaspers como determinante para a postura filosófica de Arendt: "Portanto, um exame das influências de Arendt revela que enquanto que a filosofia fenomenológica alemã seguramente teve um impacto forte na formação de seu pensamento, foi a influência de pensadores como Sócrates e Jaspers, com sua abertura para um amor mundi, que forneceu definitivamente as bases para sua atividade filosófica interativa e anti-solipsista”.
} 


\section{REFERÊNCIAS}

ARENDT, H. Men in Dark Times. New York: Harcourt, Brace and World, 1968. (Homens em Tempos Sombrios. São Paulo: Companhia das Letras, 1987). (MDT)

. The Human Condition. 2nd ed. Chicago: The University of Chicago, 1998. (A Condição Humana. 11 ed. revista. Rio de Janeiro: Forense Universitária, 2010). (HC)

Essays in Understanding (1930 - 1954) New York: Harcourt Brace and Company, 1994. (Compreender: formação, exílio e totalitarismo. Belo Horizonte: Ed. UFMG, 2008). (EU)

. The Life of the Mind. New York: Harvest Book, Harcourt, Inc., 1978. (A Vida do Espírito. 3 ed. Rio de Janeiro, Relume-Dumará, 1995). (LM)

(COR)

Correspondence with Karl Jaspers, 1926-1969. New York: Harcout Brace, 1992.

. Letters: 1925-1975. Hannah Arendt and Martin Heidegger. Harcout, 2004. (LET)

. The Jewish Writings. New York: Schocken Books, 2007. (JW)

. What is Existenz Philosophy? Partisan Review, XVIII/1, 1946. (WEP)

BETZ HUlL, M. The Hidden Philosophy of Hannah Arendt. London, New York: Routdledge Courzon, 2002.

CANOVAN, Margaret. Hannah Arendt: a reinterpretation of her political work. Cambridge: Cambridge University Press, 1992.

DUARTE, André. O pensamento à sombra da ruptura: política e filosofia em Hannah Arendt. Rio de Janeiro, Paz e Terra, 2000.

HINCHMAN, L. and HINCHMAN, S. Hannah Arendt: Critical Essays. State University of New York, 1994.

. Heidegger's Shadow: Hannah Arendt's Phenomenological Humanism. Review of Politics v. 46, n.2, 1984.

. Existentialism politicized: Arendt's debt to Jaspers. In:

Hannah Arendt:

Critical Essays. State University of New York, 1994. 
JAY, Martin. Permanent Exiles: Essays on the intellectual migration from Germany to America. New York: Columbia University Press, 1985.

TAMiniaUX, Jacques. The Thracian Maid and the Professional Thinker. Arendt and Heidegger. Albany: State University of New York Press, 1997.

VILLA, Dana. Arendt and Heidegger. The Fate of the Political. Princeton: Princeton University Press, 1996.

YOUNG-BRUHEL, E. Hannah Arendt: por amor ao mundo. Rio de Janeiro: Relume Dumará, 1997. 